\title{
Biogenic Synthesis of Silver and Gold Nanoparticles using Fungal Species
}

\author{
${ }^{1}$ Shaikh S M, ${ }^{2}$ Shaikh T J \\ ${ }^{1}$ Department of Botany, Dr. Babasaheb Ambedkar Marathwada University, Aurangabad. (MS) India. \\ ${ }^{2}$ Department of Botany, Yashwantrao Chavan College of Science, Karad. District: Satara (MS) India. \\ Corresponding Author: sannashaikh58@gmail.com
}

\section{Manuscript Details}

Manuscript Submitted : 28/04/2018

Manuscript Accepted : 12/05/2018

Manuscript Published : 15/05/2018

\section{Available On}

https://plantaescientia.website/ojs/ ISSN $2581589 \mathrm{X}$

\section{$\underline{\text { Cite This Article As }}$}

Shaikh S M \& T J Shaikh, 2018. Biogenic Synthesis of Silver and Gold nanoparticles using fungal species, Pla. Sci. 2018; Vol. 01 Issue 01: 25-30. Dol:https://doi.org/10.32439/ps.vliol.25-30

\section{Copyright}

\section{(c) (1)}

() The Author (s). 2018 Open Access This article is distributed under the terms of the Creative Commons Attribution 4.0 International License http://creativecommons.org/licenses/by/4.0/

\section{$\underline{\text { Indexed In }}$}

Google Scholar, Index Copernicus International (ICI), Directory of Research Journal Indexing (DRJI)

\begin{abstract}
Gold and Silver nanoparticles synthesized by various technique have received special attention because they have found potential application in many fields such as catalysis, sensors, drug delivery system. Additionally, silver nanoparticles possess an excellent biocompatibility and low toxicity. The present investigation has done to check out the synthetic compatibility of nanoparticles of some fungal strain i.e. Alternaria alternata, Aspergillus niger, Fusarium oxysporum, Penicillium digitatum and Penicillium spp.
\end{abstract}

Keywords: Silver Nanoparticles, Gold Nanoparticles, Alternaria, Aspergillus, Fusarium, Penicillium 


\section{INTRODUCTION}

Nanotechnology has dynamically developed as an important field of modern research with potential effects in electronic and medicine (Glomm 2005, Chan 2006, Boisselier \& Astruc, 2009). Nanotechnology can be defined as a research for the design, synthesis, and manipulation of the structure of particles with the dimension smaller than $100 \mathrm{~nm}$. Nanobiotechnology represents an economic alternative for chemical and physical methods of nanoparticles formation (Mansoori et al 2007). These methods of synthesis can be divided into intracellular and extracellular synthesis (Ahmad et al. 2003).

This integration of nanoparticles with biological molecules has to lead the development of diagnostic devices, contrast agents, and important tools in Cancer therapy (Furno et al, 2004; Shen et al, 2008). Fungus mediated biosynthesis of silver nano particles have been studied by Gitanjali \& Chavan (2014) and Morones et al, (2005) for their antibacterial activity (Shahverdi et al, 2007). Nanobiotechnology describes an application of biological systems for the production of new functional material such as nanoparticles. Biosynthetic methods can be employed either microorganism cells or plant extract for nanoparticles production.

Biosynthesis of nanoparticles is an exciting recent addition to the large repertoire of nanoparticles synthesis methods and now, nanoparticles have entered a commercial exploration period (Rai et al, 2009). Gold and silver nanoparticles are presently under intensive study for applications in optoelectronic devices, ultrasensitive chemical and biological sensors and as catalysts. Guo $\&$ Wang (2007) have worked on synthesis and electrochemical application of Gold nanoparticles.

The term "Nano" has been originated from the Greek word meaning dwarf ie. small things. The science and technology of small things called as nanotechnology (Goodsell, 2004). Therefore, Nanotechnology is the branch of science deals with the study of various aspects of research and technology.

The concept and ideas of Nanoscience and Nanotechnology firstly used by the great Physicist Richared Feynamn at an American physical society meeting at the California Institute of Technology on 29 December, 1959. Nanotechnology combines such as Physics, Chemistry, Electric Engineering, Chemical Engineering, Bioscience, Biophysics and Material Science. The Technology behind the Nano is very much important due to their small size (>100 Nanometer), unique properties and control the structure and composition of the Nanometer (nm) scale.

\section{MATERIAL AND METHODS}

Fungal species were collected from different soil, abnormal seeds and deteriorated plants of different localities of Marathwada.

Seed sample- The method described by Neergard (1973) has been adopted for the collection of the seeds samples. Accordingly, seeds with different abnormalities were collected from the field as well as markets of some Districts in Marathwada region of Maharashtra.

Deteriorated plant parts - The different deteriorated plant Parts, like Root, Stem, Leaves, and Fruits were collected from Garden, markets and field. Infected part washed with the sterile Distilled water and cuts into small pieces.

Plant debris - The plant debris also collected for the isolation of fungal strains. Collected fungal samples of seeds, deteriorated plant parts and plant debris was detected by Agar plate and Blotter test method with Potato Dextrose Agar (PDA), Glucose nitrate (GN) and Czpek Dox Agar (CZA) media. Presence and absence of fungal species were noted in Table 01 .

\section{Characterization \& Identification of Fungal Species}

All fungal isolates were obtained in pure cultures by using standard techniques. The photomicrographs of all the fungal isolates were taken helps in identification of the fungal isolates. The cultural characteristics and the sporulating structures of these isolates are presented in Five fungal isolates were identified as, Alternaria alternata, Aspergillus niger, Fusarium oxysporum, Penicillium digitatum and Penicillium spp. Detailed examination of fungal characters was done under the compound microscope and their identification was made with the help of manuals and literature. The Pure culture of these fungal species (Plate I) was prepared and maintains on PDA slant.

\section{Nanoparticles Production}

\section{a) Production of Biomass}

The Nanoparticles production was studied by growing the fungi on liquid GN medium, $40 \mathrm{ml}$ or GN medium was pure in Io $\mathrm{ml}$ of conical flask and autoclave at $150 \mathrm{lbs}$ pressure for $30 \mathrm{~min}$. then the mask was inoculated separately with $1 \mathrm{ml}$ spore suspension of the fungi which was grown for 7 days on PDA slant. Unless other vice stated, the flask were incubated for 6 days at $30^{\circ} \mathrm{C}$ on a rotary shaker also on $7^{\text {th }}$ day the flask were harvested by filtering the biomass through pre-weight Whatman filter paper No. 1 and those extensively washed with sterile Dry to remove any 
medium components. The fungus biomass is used for the preparation of cell free extract.

\section{b) Synthesis of Silver Nanoparticles}

Fresh and clean biomass were taken in a conical flask containing $40 \mathrm{ml}$ of double distilled water and incubated $26 \mathrm{c}$ with shaking on rotary shaker $150 \mathrm{rpm}$ ) for 72 hours. After then the biomass was filtrate again with Whatman filter paper No. $\mathrm{Ol}$ and cell-free filtrate was collected in the flask. Silver nitrate, Chloro-uric acid and copper Chloro-uric acid and copper Sulphate most wildly used as a source of Silver ions.

The $1 \mathrm{ml}$ of aqueous solution of Silver nitrate $\left(\mathrm{AgNo}_{3}\right)$, Chloro-uric acid $\left(\mathrm{HAuCl}_{4}\right)$ and Copper sulphate $\left(\mathrm{CuSO}_{4}\right)$ was used for the synthesis of Silver $10 \mathrm{ml}$ of cell-free filtrate of fungi in conical flask separately. Those flasks were incubated at room temperature in dark condition to minimize the photo-activation of metal ions. Control (Without metal ions) was also run along with the experimental flask.

\section{c) Synthesis of Gold Nanoparticles}

Gold nanoparticles were prepared in surfactant solutions by reduction of $\left(\mathrm{HAuCl}_{4}\right)$ under UV radiation without adding extra reductants or other organic substances. It was found that the longer the alkyl chain of the surfactant, the larger gold particles are obtained. The formation of product mycelium composed of the charged surface-active portion of the surfactant molecule and the $\left(\mathrm{Au}_{3} \mathrm{Cl}_{4}\right)$ - ion in cationic surfactant solution serves as the Gold source and favours the formation of Gold particles with larger sizes. While the repulsion between the $\left(\mathrm{Au}_{3} \mathrm{Cl}_{4}\right)$ - ion and the negative charged surface of anionic surfactant micelle is in favour of the formation of gold nanoparticles with smaller sizes. The non-ionic surfactants can also assist the formation of dispersed gold nanoparticles

\section{d) Characterization of Silver and Gold Nanoparticles}

i) Visual Analysis of Nanoparticles - It is done by present or absence of Nanoparticles by a specific colour.

ii) UV Spectrophotometric Analysis - The reduction of ion was confirmed by UV-visible spectrophotometer. $1 \mathrm{ml}$ of sample was withdrawn after $24 \mathrm{~h}$. The reduction of ions to Nano-particles (by Alternaria alternata, Aspergillus niger, Fusarium oxysporum, Penicillium digitatum and Penicillium spp.

iii) Incidence of fungi from different deteriorated plant parts - Naturally infected plant parts like Stem, Leaves and Fruit were collected from different localities. Infected plant parts were cut into small pieces wash with $\mathrm{D} / \mathrm{W}$ incubated on PDA media at $30^{\circ} \mathrm{C}$ for 7 days. Process of biosynthesis of nanoparticles, cultural filtrate and visual analysis is photographed in Plate 02 (Kowshik et al, 2002).

Fourier Transform Infrared (FTIR) Spectrometer by Bruker (Model No. Alfa II) is used to confirm the absorption or emission from the material.

\section{RESULTS AND DISCUSSIONS}

The $10 \mathrm{ml}$ cell-free extract of fungi immersed with $10 \mathrm{ml}$ of $\mathrm{lml}$ solution $\mathrm{AgNO}_{3}$ and $\mathrm{HAuCl}_{4}$ in the separate set of flasks for the Synthesis of Silver and Gold nanoparticles respectively, after immersion, colour of cell-free extract become changed from previous colour to different shades of colour. The colour range developed for Silver nanoparticles was Violet-pink, Grey, Light-grey, and Brown-red etc. The colour range developed for Gold nanoparticles was Light Orange, Brownish-orange, Orange-yellow and Light Yellow etc. Observations were recorded in Table 02. The optimum wavelength for nanoparticles production was determined; the reduction of Silver ions was confirmed by qualitative testing samples by UV-visible spectrophotometer. The $1 \mathrm{ml}$ sample of nanoparticles was withdrawn after 24 hours and absorbance was measured $350-550 \mathrm{~nm}$.

\section{CONCLUSION}

In this experimental investigation the Silver Nanoparticle were synthesized (extra cellular) by Alternaria alternata, Aspergillus niger, Fusarium oxysporum, Penicillium digitatum and Penicillium spp. At room temperature the AgNPS quite stable without using any toxic chemical as capping agent and shows broad spectrum at Silver $440 \mathrm{~nm}$ the ability to synthesis the AgNPS as potential agent using a selected fungal species is highly promising for the green sustainable production of Nanometals and also enhance its wide spread application as an important strategy. The FTIR result (Graph 05, \& 06) indicates two peaks from spectra for Gold nanoparticle mean this indicates the presence of gold nanoparticles in the synthesized from Alternaria alternate and Fusarium oxysporum. Two peaks in the spectra represented in Graph 01, 02, 03 and 04 indicates the presence of Silver nanoparticles synthesized from Penicillium digitatum, Fusarium oxysporum and Alternaria alternate.

\section{ACKNOWLEDGEMENTS}

Authors wish acknowledge Head, Department of Botany, Dr. Babasaheb Ambedkar Marathwada University, Aurangabad and Principal, Yashwantrao Chavan College of Science Karad, to grant the permission to carry out research work in the department and encouragement. 
Table 01: Isolation of Fungal Species from the Different Plant Materials

\begin{tabular}{|c|l|c|c|c|}
\hline $\begin{array}{c}\text { Sr. } \\
\text { No. }\end{array}$ & Name of fungi & Seed & Plant parts & Plant Debris \\
\hline $\mathbf{l}$ & Alternaria alternata & + & + & - \\
\hline 2 & Aspergillus niger & + & + & + \\
\hline 3 & Fusarium oxysporum & + & + & + \\
\hline 4 & Penicillium digitatum & - & + & - \\
\hline 5 & Penicillium spp. & - & + & - \\
\hline
\end{tabular}

Note: Presence of Fungi from different plant materials denoted as '+' and 's' shows absence of fungal species.

Table 02: Visual Detection Method in Biosynthesis of Silver and Gold Nanoparticles

\begin{tabular}{|c|l|c|c|c|}
\hline $\begin{array}{c}\text { Sr. } \\
\text { No. }\end{array}$ & Name of Fungus & $\begin{array}{c}\text { Fungal Mat } \\
\text { Colour }\end{array}$ & $\begin{array}{c}\text { After Addition of } \\
\mathrm{AgNO}_{3}\end{array}$ & $\begin{array}{c}\text { After Addition of } \\
\mathrm{HAuCl}_{4}\end{array}$ \\
\hline $\mathbf{l}$ & Alternaria alternata & Rosy-white & Light Orange-Yellow & Violet Pink \\
\hline 2 & Aspergillus niger & Black & Brown Orange & Brown Red \\
\hline 3 & Fusarium oxysporum & Pink & Light Orange & Grey \\
\hline $\mathbf{4}$ & Penicillium digitatum & Green & Orange Yellow & Light Grey \\
\hline 5 & Penicillium spp. & Green & Light Yellow & Light Grey \\
\hline
\end{tabular}

\section{REFERENCES}

Ahmad A, Mukherjee P, Senapati S, Mandal D, Khan M I, Kumar R, Sastry M, 2003. Extracellular biosynthesis of silver nanoparticles using the fungus Fusarium oxysporum, Colloids Surfaces, B: Biointerfaces, 27, 313-318 doi: https://doi.org/10.1016/S0927-7765(02)00174-1

Boisselier E, Astruc D, 2009. Gold nanoparticles in nanomedicine: preparation, imaging, diagnostics, therapies and toxicity, Chem. Soc. Rev., 38,1759-1782. doi: https://doi.org/10.1039/B806051G

Chan W C W, 2006. Bionanotechnology progress and advances, Biology Blood Marrow Transplantation, 12, 87-91

doi: https://doi.org/10.1016/j.bbmt.2005.10.004

Furno F, Morley K S, Wong B, Sharp B L, Howdle S M, Roger Bayston Paul D. Brown Peter D. WinshipHelen J. Reid 2004. Silver nanoparticles and polymeric medical devices: a new approach to prevention of infection, J. Antimicrob. Chemother., 54, 1019-1024 doi: https://doi.org/10.1093/jac/dkh478

Gitanjali B Shelar \& Ashok M Chavan, 2014. Fungus mediated biosynthesis of silver nano particles and its antibacterial activity. Jour. Archives CODEN (USA), 6(2): pg. 111-114.

Glomm R W, 2005. Functionalized nanoparticles for application in biotechnology, J. Dispersion Sci. Technology, 26, 389-314

Goodsell D S, 2004. Bio-nanotechnology: Lessons from Nature, Wiley-Liss, Hoboken, New York.
Guo S, Wang E, 2007. Synthesis and electrochemical application of gold nanoparticles, Analytica Chimica Acta, 598, 181-192 doi: https://doi.org/10.1016/j.aca.2007.07.054

Kowshik M, Vogel W, Urban J. Kulkarni S K, Paknikar K M, 2002. Extracellular Synthesis of Silver Nanoparticles by a Silver-Tolerant Yeast strain MKY3. Adi, Mater... 14. pg. 812-815. Doi: https://doi.org/10.1088/0957$\underline{4484 / 14 / 1 / 321}$

Mansoori G A, George T F, zhang G and Assoufid L, 2007. Molecular Building Blocks for Nanotechnology, Springer, New York. DOI: https://doi.org/10.1007/978-0-387-39938-6

Morones J R, Elechiguerra L J, Camacho A, Holt K, Kouri B J, Ramirez T J, Yocaman J M, 2005. The bactericidal effect of silver nanoparticles, Nanotechnology, 16, 2346-2353 doi: https://doi.org/10.1088/0957$\underline{4484 / 16 / 10 / 059}$

Rai M, Yadav A, Gade A, 2009. Silver nanoparticles as a new generation of antimicrobials, Biotechnology Advances, 27, 76-83 doi: https://doi.org/10.1016/j.biotechadv.2008.09.002

Shahverdi R A, Fakhimi A, Shahverdi H R, Minaian S, 2007. Synthesis and effect of silver nanoparticles on the antibacterial activity of different antibiotics against Staphyloccocus aureus and Escherichia coli, Nanomed: Nanotechnol. Biol. Med., 3, 2, 168-171 doi: https://doi.org/10.1016/j.nano.2007.02.001

Shen Q, Wang X, Fu D, 2008. The amplification effect of functionalized gold nanoparticles on the binding of cancer drug decarbazine to DNA and DNA bases, Applied Surface Sci., 255, 577-580 doi: https://doi.org/10.1016/j.apsusc.2008.06.132 

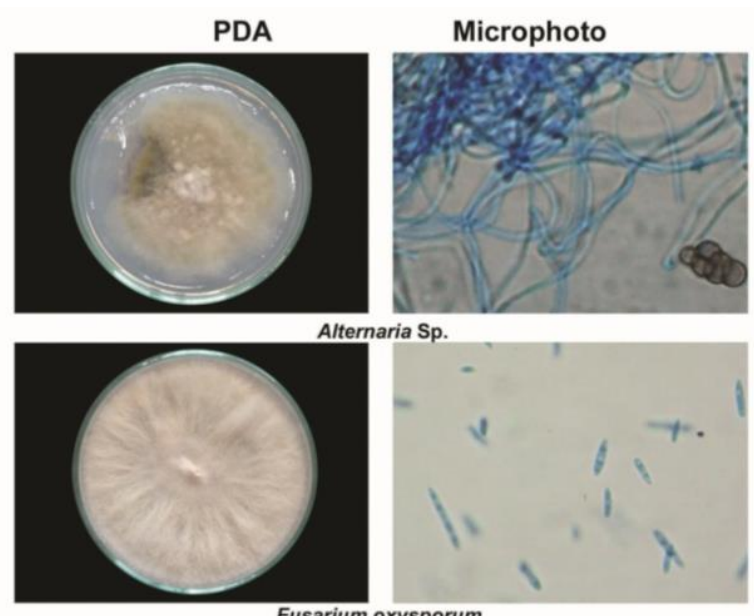

Fusarium oxysporum

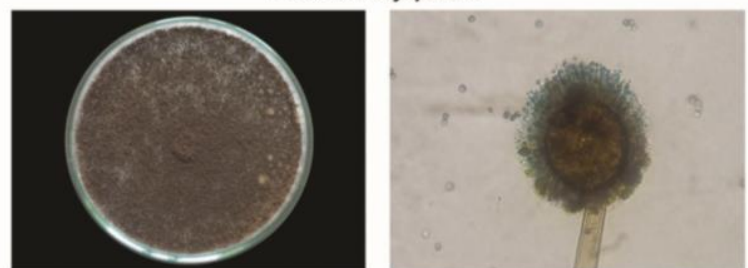

Aspergillus nigar

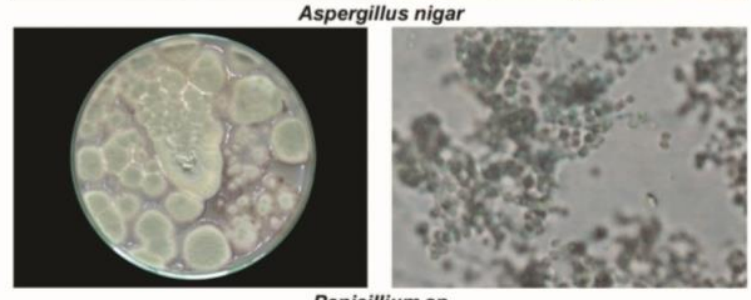

Penicillium sp.

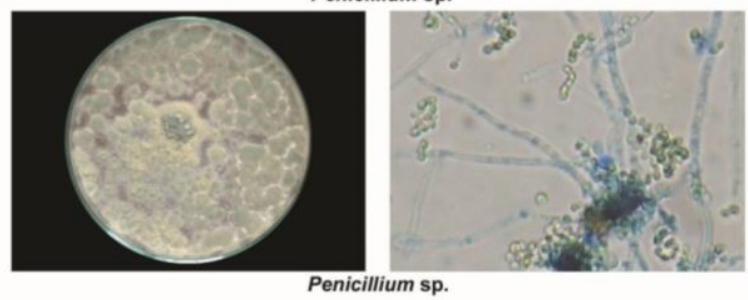

PLATE 01

Selected fungal species on media for Isolation, Characterization \& Identification.
Process of Nanopartical Biosynthesis

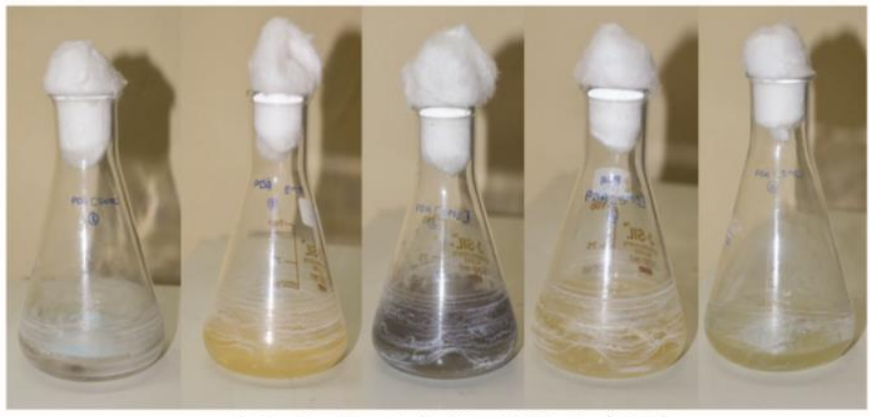

Selective Fungi On Liquid Media (PDA)

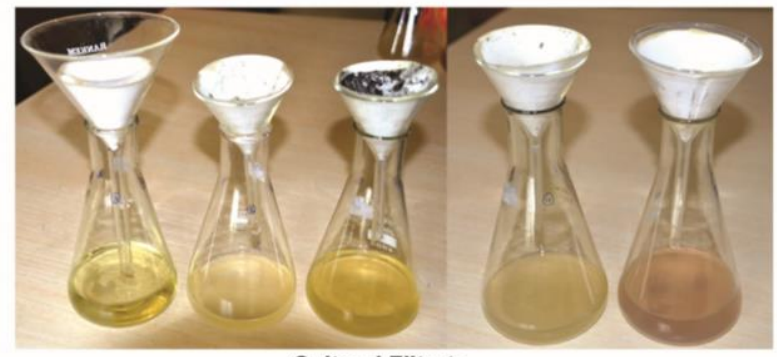

Cultural Filtrate

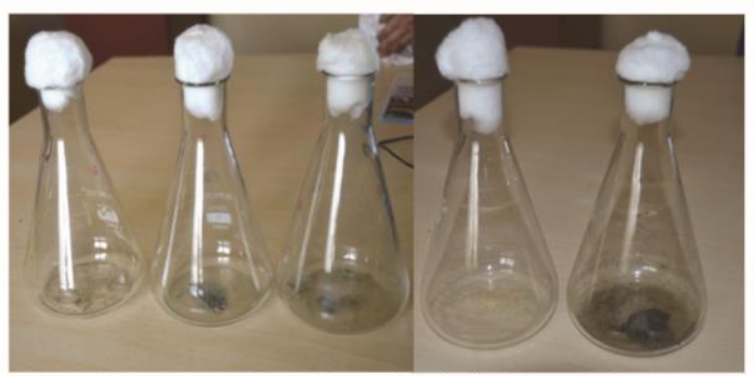

Visual Analysis of Biosynthesis Nanopartical

PLATE 02

Process of Nanoparticle Biosynthesis

1. Selective Fungal species on Liquid Media (PDA)

2. Cultural Filtrate

3. Visual Analysis of Biosynthesis of Nanoparticles 


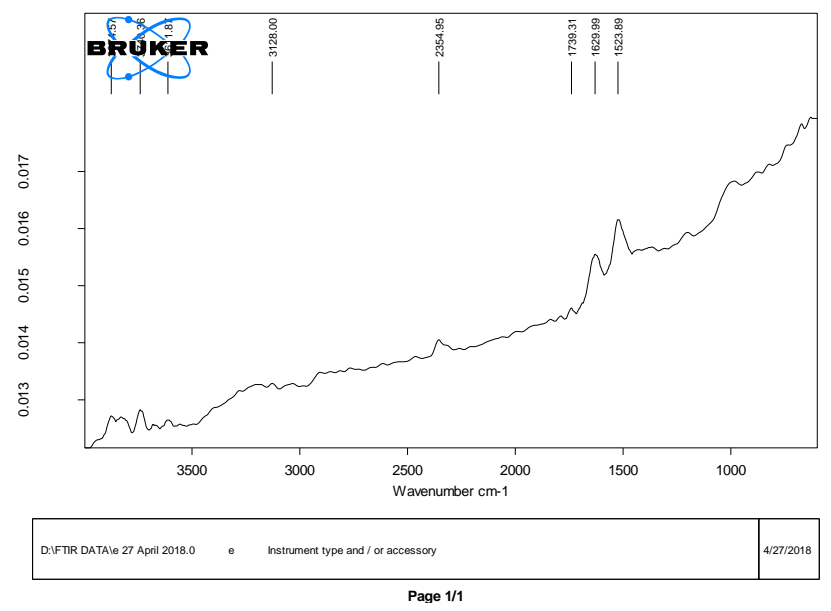

Graph 01: Effect of Different Wavelengths on Silver Nanoparticle Production in Penicillium digitatum

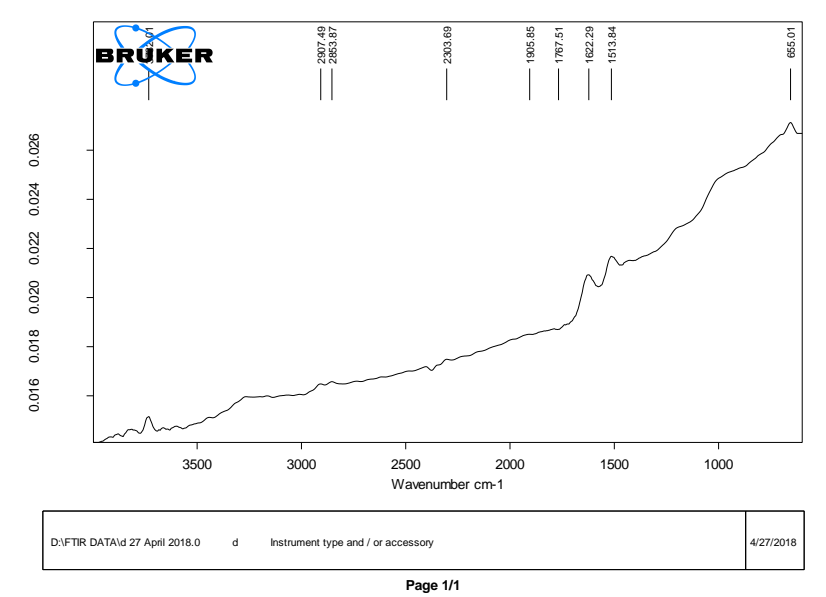

Graph 02: Effect of Different Wavelengths on Silver Nanoparticle Production in Penicillium spp.

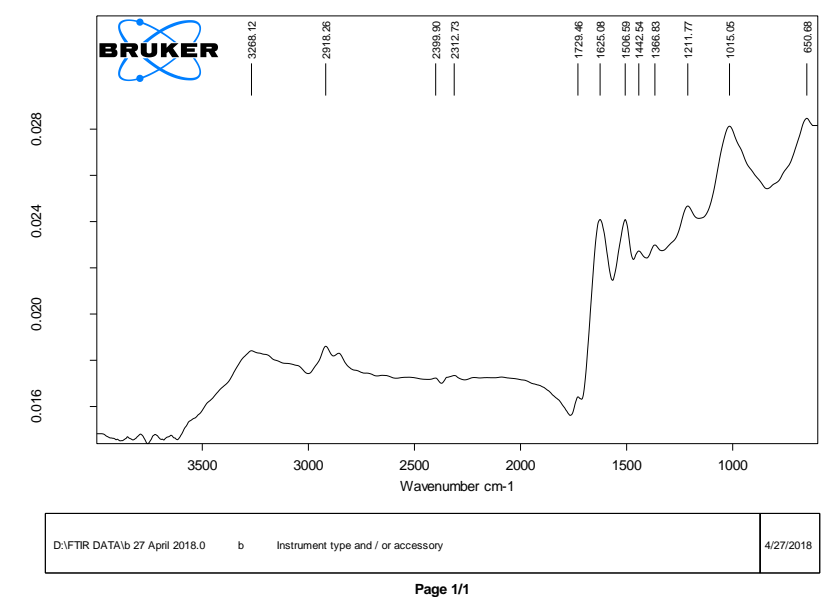

Graph 03: Effect of Different Wavelengths on Silver Nanoparticle Production in Fusarium oxysporum

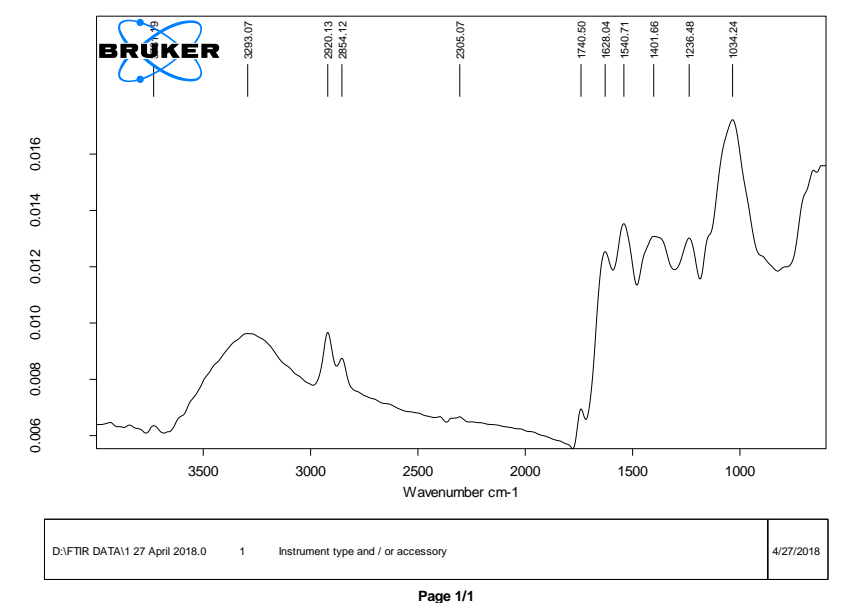

Graph 04: Effect of Different Wavelengths on Silver Nanoparticle Production in Alternaria alternata

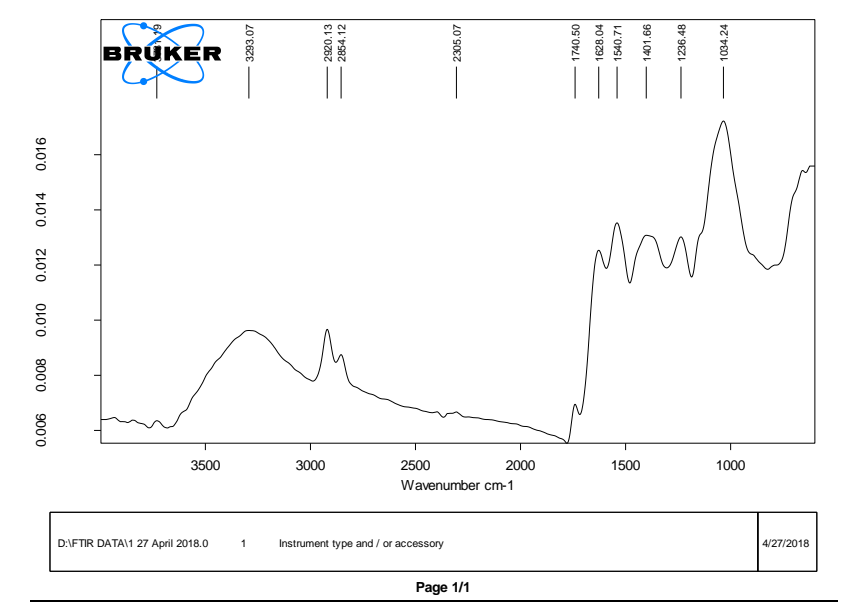

Graph 05: Effect of Different Wavelengths on Gold Nanoparticle Production in Alternaria alternata

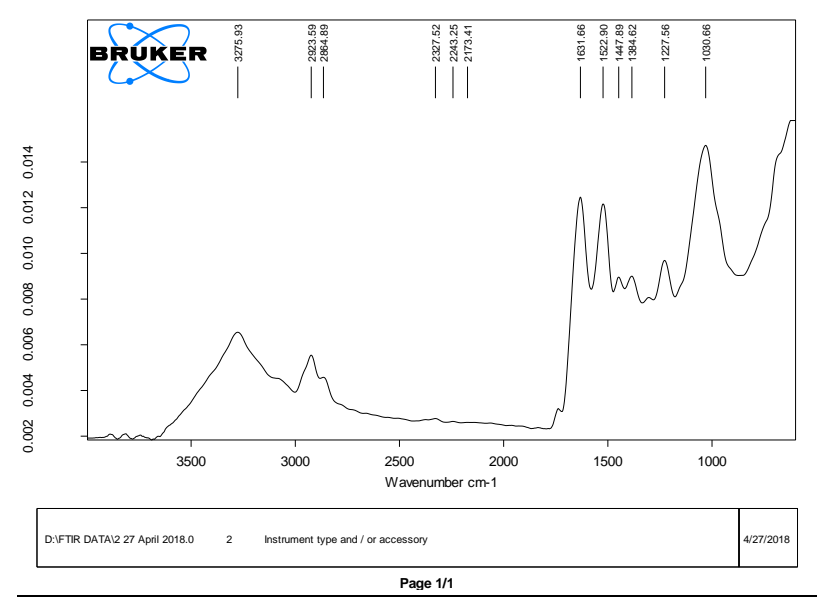

Graph 06: Effect of Different Wavelengths on Gold Nanoparticle Production in Fusarium oxysporum

c 2018| Published by Plantae Scientia 